\title{
The National Network of Congenital Anomalies: Extended goals for surveillance
}

In a previous article ${ }^{1}$ we presented the National Registry of Congenital Anomalies (Registro Nacional de Anomalías Congénitas de Argentina, RENAC), a surveillance system for major congenital anomalies (CAs). The RENAC was created in 2009 in response to the growing incidence of CAs as a cause of infant morbidity and mortality. In Argentina, the relative relevance of CAs has increased over the past decades as a cause of infant mortality: in 1980, CAs accounted for $11 \%$ of deaths among infants younger than 1 year old while in 2014, they accounted for $28 \%$. Seeking to collect information on morbidity, and following a pilot study, ${ }^{2}$ the RENAC was created and granted the role of "registry" focused on generating epidemiological information and with the purpose of establishing the rate of major CAs among newborn infants and stillbirths and monitoring epidemiological alerts. ${ }^{3}$ Every year the RENAC publishes reports on CA prevalence in Argentina, by jurisdiction and by specific CA (RENAC Report, 2015), in addition to scientific publications. ${ }^{1,4}$

The RENAC is made up of a central coordination department and a maternity center network; in each maternity center, there are two healthcare providers working in newborn infant care (neonatologists, pediatricians, nurses) who report CA cases and number of births to the coordination department on a monthly basis. The system's simplicity was prioritized; it does not collect risk factors on a routine basis but seeks to provide wide coverage and high diagnostic quality based on CA description and coding by geneticists of the coordination department.

The purpose of this comment is to describe the extended goals of the RENAC surveillance system, which in 2015 was no longer a "registry" but the National Network of Congenital Anomalies. Even though from the beginning the system had a network-like design, over time we became aware of the importance of improving our communications and enlist new participants. In 2010, we introduced an online forum system, a participatory asynchronous communication technology which allows publishing customized messages, thus shortening distances. Healthcare providers from the different maternity centers publish information, and the coordination department provides guidance and raises issues on the initial diagnosis of affected newborn infants. In turn, and since the onset, geneticists from different provinces, other jurisdictional areas, and Ministry of Health sectors were invited to participate. This improvement in communication and the association with other healthcare parties allowed the RENAC to move past its initial objective of describing CA rates and focus on the following extended goals:

- To connect patients with CAs with the healthcare system: the online forum was initially used to connect newborn infants with CAs with local geneticists so that a diagnosis could be made and genetic counseling provided. In 2015, and by means of an association with the SUMAR Program (www.msal.gob.ar/ sumar), the Network for the care of oral clefts, club foot and developmental dysplasia of the hip was created. To this end, interdisciplinary groups treating these CAs were invited to be part of the system. Newborn infants born with these CAs are reported by maternity center healthcare providers, and the coordination department, in conjunction with their families and treating teams, refers them and coordinates their follow-up. The SUMAR Program provides its experience in healthcare services, the funds for each healthcare provider for their services, and invites providers to participate in the healthcare network coordination.

- To estimate the impact of the main CAs so as to assess resource needs: based on the prevalence of specific CAs observed by the RENAC, the expected number of annual cases of selected CAs was estimated given their clinical relevance: Down's syndrome, talipes equinovarus (club foot), oral clefts, severe heart diseases, abdominal wall defects, intestinal atresias, and spina bifida. ${ }^{5}$ This information is relevant for all jurisdictions and healthcare providers responsible for planning healthcare services provided to patients with these CAs.

- To determine newborn infant survival: the RENAC conducted a study to estimate the rate of infant deaths caused by a group of CAs, selected according to their higher impact 
on morbidity and mortality, their prevalence, and because they are reducible through medical/surgical interventions: encephalocele, spina bifida, gastroschisis, omphalocele, diaphragmatic hernia, esophageal atresia, intestinal atresia, and anorectal malformation. Estimated lethality rates are used as indicators to assess health interventions, as a resource for prenatal or neonatal referral services, and to establish differences in survival which may be related to risk factors. In this study, gastroschisis was the most prevalent CA while diaphragmatic hernia was the CA with the highest lethality rate. Prematurity and socioeconomic hardship variables increased the risk of death among affected infants. ${ }^{6}$

- To train healthcare providers: the RENAC has implemented three strategies. 1. Training based on reported cases: the coordination department provides guidance on the initial management and likely diagnosis to healthcare providers from the maternity centers. 2. Blended learning courses: online courses with face-to-face assessments to approach CAs from the perspective of public health, epidemiology, dysmorphology, and etiology. The participation of 153 healthcare providers from the 24 Argentine jurisdictions has resulted in improvements in detection, care, and description of affected newborn infants and encourages RENAC participants to become involved. 3. An annual meeting of RENAC members to present its annual report, provide updates on topics of interest, and conduct operational improvements.

- To promote health: the population plays a major role, so the RENAC has interacted with associations of families and patients with CAs and has developed an agenda to help the families of patients with oral clefts with their follow-up throughout their long-term treatment. In addition, in 2016, the RENAC has started using online social networks to disseminate information on CAs.

- To study the impact of population interventions: $50 \%$ of CAs are preventable, and there are effective interventions that can be implemented at a population level for their primary prevention, such as food fortification with folic acid to prevent neural tube defects. In Argentina, wheat flour and food product fortification is mandatory as per National Law no. 25630 (2002). Based on the RENAC's information, it has been confirmed that folic acid fortification has provided a protective effect: anencephaly and encephalocele decreased by $66 \%$, and spina bifida, by $47 \% .{ }^{7,8}$

To sum up, the National Network of Congenital Anomalies, initially developed as an epidemiological registry, has now extended its initial objective and included other goals in relation to healthcare, health promotion, training, and intervention assessment. To achieve these objectives, the RENAC has increased the number of participating healthcare providers and has established associations with providers from the different provinces and at a central level. Since 2013, the RENAC has been a member of the International Clearinghouse for Birth Defects Surveillance and Research (www.icbdsr. org) and EUROCAT (www.eurocat-network. $\mathrm{eu})$, two international committees established for CA surveillance and prevention. Such extension of the RENAC's objectives together with networking favor its sustainability, goodquality information, and essentially allow to implement actions across the 24 Argentine jurisdictions aimed at providing timely care to patients with CAs. The RENAC's 651 members' commitment is achieved through training sessions, feedback on processed information, and support on the initial management, diagnosis and follow-up of affected newborn infants. This surveillance system is based on individuals' ongoing commitment, not only in relation to the generation of epidemiological information but also the narrowing of inequalities.

Boris Groisman, M.D., María P. Bidondo, M.D., Pablo Barbero, M.D., Rosa Liascovich, M.D. National Genetic Medicine Center (Centro Nacional de Genética Médica, CNGM), National Administration of Health Institutes and Labs (Administración Nacional de Laboratorios e Institutos de Salud, ANLIS), Ministry of Health. bgroisman@gmail.com

http:/ /dx.doi.org/10.5546/aap.2016.eng.295

\section{REFERENCES}

1. Groisman B, Bidondo MP, Barbero P, Gili J, Liascovich R. Registro Nacional de Anomalías Congénitas de Argentina. Arch Argent Pediatr 2013;111(6):484-94.

2. Liascovich R, Gili JA, Valdez R, Somaruga L, et al. Desarrollo de un registro nacional de anomalías congénitas: estudio piloto de factibilidad. Rev Argent Salud Pública 2011;2(6):6-11. 
3. Groisman B, Liascovich R, Gili J, Barbero P, Bidondo MP, RENAC Task Force. Sirenomelia in Argentina: prevalence, geographic clusters and temporal trends analysis Authors. Birth Defects Res A Clin Mol Teratol. In press.

4. Groisman B, Bidondo MP, Gili J, Barbero P, Liascovich R. Strategies to Achieve Sustainability and Quality in Birth Defects Registries: The Experience of the National Registry of Congenital Anomalies of Argentina. J Registry Manag 2013;40(1):29-31.

5. Bidondo MP, Groisman B, Gili J, Liascovich R, Barbero P. Prevalencia de anomalías congénitas en Argentina y su potencial impacto en los servicios de salud. Rev Argent Salud Pública 2014;5(21):38-44.
6. Bidondo MP, Groisman B, Gili JA, Liascovich R, Barbero P. Estudio de prevalencia y letalidad neonatal en pacientes con anomalías congénitas seleccionadas con datos del Registro Nacional de Anomalías Congénitas de Argentina. Arch Argent Pediatr 2015;113(4):295-302.

7. Sargiotto C, Bidondo MP, Liascovich R, Barbero P, Groisman B. Descriptive Study on Neural Tube Defects in Argentina. Birth Defects Res A Clin Mol Teratol 2015;103(6):509-16.

8. Bidondo MP, Liascovich R, Barbero P, Groisman B. Prevalencia de defectos del tubo neural y estimación de casos evitados posfortificación en Argentina. Arch Argent Pediatr 2015;113(6):498-501. 